\title{
Robert A. Laudise Named Editor-in-Chief of Journal of Materials Research
}

Robert A. Laudise has been named editor-in-chief of the Journal of Materials Research, an international publication which covers the physics, chemistry, and engineering of advanced materials and materials processing techniques. Laudise will succeed current editor-in-chief Walter L. Brown of AT\&T Bell Laboratories on January 1, 1994.

$I M R$ is the official publication of the 11,500-member Materials Research Society. "JMR is only eight years old," said Laudise, "and is on a steady upward trajectory in its role as the premier journal in the field. My goal is to continue that trajectory, so ably established by the first two editors, Charlie Duke and Walter Brown, and to assure that JMR is the place where people publish their definitive papers on the newest areas of materials science.

"IMR is blessed with an excellent editorial office, led by Linda Krysinski, and outstanding associate and principal editors," he said.

MRS president S. Tom Picraux welcomed the appointment of Laudise as editor-in-chief of $J M R$. "Bob Laudise is a highly respected leader in the field of materials research, and we are delighted he has agreed to take over the helm of $J M R$. Bob's strong interdisciplinary approach and impressive breadth of knowledge of materials will be invaluable to the JMR team. Charlie Duke and Walter Brown will not be easy to follow as editor-in-chief, but I know that Bob will continue to lead this publication to new heights."

Laudise is currently adjunct research director for chemistry at Bell Labs, which

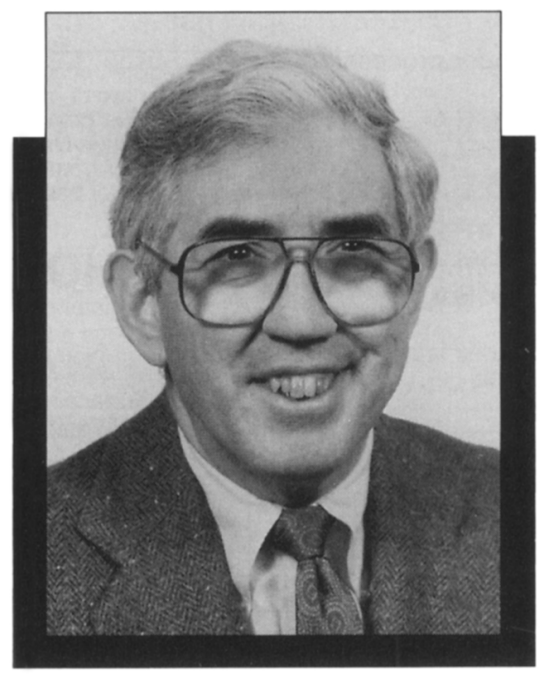

he joined in 1956 after receiving his $\mathrm{PhD}$ degree in chemistry at the Massachusetts Institute of Technology. He is a member of both the National Academy of Science and the National Academy of Engineering. He received his $\mathrm{BS}$ degree in chemistry from Union College in Schenectady, New York.

Earlier in his career, Laudise conducted the first studies of the physical chemistry of high-temperature, high-pressure supercritical aqueous solutions as applied to crystal growth, which led to an understanding of quartz crystallization. This process made possible the successful worldwide commercial growth of quartz for electronic applications.
His systematic studies of the defect structure and take-up of impurities by quartz led to piezoelectric devices with properties generally superior to those of natural quartz. Laudise's recent research is on the preparation of nonlinear optical and optical amplifier materials for communication applications. He is the author of The Growth of Single Crystals, a classic text which systematizes crystal growth and provides theoretical underpinnings.

Laudise is also an adjunct professor of materials science at both MIT and Rutgers University, and has been a visiting professor at Shandong University in China and Hebrew University. He currently is an advisor to the Department of Energy, the National Aeronautics and Space Administration, and the PhD program at Alabama $A$ and $M$ University, which is among the largest sources of African-American physicists in the United States.

At Bell Labs, Laudise has conducted fundamental research in the physical chemistry of crystal growth, including setting up the pilot plant for quartz crystal growth. He has led groups whose research produced high transition temperature superconductors, the first mode dispersion-controlled optical fibers, the lowest threshold optically pumped laser (YAG-Nd), and the most efficient and widely used electrooptic modulator (lithium niobate).

Laudise's recent interests include applying quality concepts to research, and developing both corporate and national strategies for industrial ecology-environmental responsibility in product design and manufacture.

\section{Walter L. Brown Praised for Leading JMR}

The president of MRS had high praise for the retiring editor-in-chief of $J M R$. "I first met Walter Brown as a graduate student, and from the beginning found him both a mentor and a person to emulate," said S. Tom Picraux. "With the depth and breadth of his science, his inventive engineering bent, and the personal commitment he gave to everything he did, Walter kept us all in awe. In his contributions to MRS, particularly during the last seven years as editor-inchief of $J M R$, he has continued to uphold those high standards.

"Under Walter Brown's leadership, JMR has become one of the major materials journals. It is a scientific journal of both high quality and high visibility. Although $J M R$ has been in existence for only eight years-a short time as journals go-it is already well on its way to becoming the premier journal for the publication of interdisciplinary materials research."

\section{Deadline for MRS 1993 Fall Meeting Preregistration: November 19, 1993}

